\section{BIBLIOTECA JORGE D. WLLIAMS}

J. Zool. Syst. Evol. Research 41 (2003) 152-156 (c) 2003 Blackwell Verlag, Berlin ISSN 0947-5745

${ }^{1}$ Dept. Cs. Naturales, Univ. Nac. Rio Cuarto, Córdoba, Argentina; ${ }^{2}$ Unidad de Ecologia Animal, IADIZA (CONICET). CC. 507 , 5500, Mendoza, Argentina, ${ }^{3}$ Centro de Biologia Ambiental/DZA, Fac. Ciências. Univ. Lisboa. Campo Grande, Lisboa, Portugal;

${ }^{4}$ Present address: Hilario Cuadros 81, 5501, Godoy Cruz, Mendoza, Argentina.

\title{
From oviparity to viviparity: a preliminary note on the morphometric differentiation between oviparous and viviparous species assigned to the genus Liolaemus (Reptilia, Squamata, Liolaemidae)
}

\author{
J. M. CEI ${ }^{1,4}$, F. VIDELA ${ }^{2}$ and L. VICENTE ${ }^{3}$
}

\begin{abstract}
Embryonic growth requires a considerable internal space in viviparous female lizards and this need for space should be reflected in their external morphometry. External morphological differences associated with the reproductive mode in 12 viviparous and 18 oviparous species of Liolaemus lizards were identified. Size differences between viviparous and oviparous species were elucidated by axilla-groin/snout-vent relationship. Axillagroin distance, considered a size estimator of visceral cavity, surpassed $50 \%$ of snout-vent length in viviparous females, while it is always less than $50 \%$ in oviparous females. This difference between the two reproductive modes is statistically significant.
\end{abstract}

Key words: Liolaemus - morphometry - reproductive modes - oviparous - viviparous

\section{Introduction}

In the South American herpetofauna, the widely distributed genus Liolaemus (Liolaemidae family) has been the subject of recent studies, considering its evolutionary features and its striking speciation patterns, since glacial times until today. About 160 taxa have been described, from the Peruvian highlands to Tierra del Fuego, from the Pacific Coast to the Atlantic shores (Cei 1986; Etheridge 1995). Among them, a remarkable percentage of viviparous taxa have been reported, mainly from the Andean and Patagonian biotas, and thus from strongly seasonal climates, with cold or very cold winter periods (Cabrera and Willink 1980).

Several authors (Tinkle and Gibbons 1977; Guillette 1982; Shine 1983,1995$)$ have attempted to point out the possible adaptive value of viviparity in the presence of very cold environmental conditions, and/or hydric stress.

According to Blackburn (1993b, 1998b), viviparous squamates exhibit numerous plesiomorphic features that predispose them towards the evolution of viviparity: vascularized oviducts that can house foetuses during development, low metabolic rates, facultative egg-retention (Callard et al. 1992), extraembryonic membranes that function in gas exchange and embryonic tolerance of hypoxia during birth. Blackburn (1995) and Shine (1983) consider that, by retaining embryos through the limb bud stage, oviparous squamates in general have evolved towards viviparity.

Viviparity can provide a better embryonic development by increasing the length of gestation. In the species where placenta-like structures can be assumed, an additional body cavity space could be required for embryonal development.

Therefore, as the volume and mass of advanced foetuses is greater than that of eggs, it is to be expected that evolution would favour a change in maternal body shape.

According to Blackburn (1999), the origin of viviparity in squamates does not appear to require the acquisition of complex adaptations for foetal nutrition or respiration. Instead, its evolution requires very few structural and functional changes: an increase in the duration of oviductal egg retention, a reduction in eggshell thickness, and possibly an increase in vascularization of the oviduct and chorioallantois. These modifications presumably require little genetic change, which explains why oviparous and viviparous forms can be found within the same genus, and sometimes in separate populations of the same species. The microevolutionary nature of these changes is consistent with the view that viviparity evolves via punctuated equilibria, with intermediate stages being evolutionarily unstable (Blackburn 1995, 1998a).

Recently, de Fraipont et al. $(1996,1999)$ performed an analysis of 24 genera and suggested a potential relationship between body size and reproductive mode. They found a correlation between the evolution of viviparity and a decrease in body size. However, they only compared one single oviparous species of the genus Liolaemus with the mean snout-vent length (SVL) of nine viviparous forms of the same genus.

In the present paper, the body cavity space in the viviparous as well as in the oviparous species was considered, in order to evaluate its relationship with possible morphometric differences. Females of viviparous and oviparous taxa were compared and results of the morphometric research were analysed and discussed.

\section{Materials and method}

The present study was initially based on a set of 371 oviparous and viviparous female specimens belonging to 33 taxa of the genus Liolaemus. Viviparity, in this context includes all live-bearing species, regardless of the degree of placentotrophy (Shine and Lee 1999).

The oviparous species were: L. anomalus, $L$. bibroni, $L$. boulengeri, L. chacoensis, L. chiliensis, L. cuyanus, L. darwinii, L. fitzingeri, L. fuscus, L. gracilis, L. insolitus, L. melanops, L. pseudoanomalus, L. quilmes, L. riojanus, $L$. rothi, $L$. sanjuanensis, $L$. scapularis, $L$. tenuis, $L$. uspallatensis and $L$. xanthoviridis. The viviparous species were: $L$. archeforus, L. baguali, L. gallardoi, L. kingii, L. lineomaculatus, L. magellanicus, L. ornatus, L. periglacialis, L. pictus, L. sarmientoi, L. (Vilcunia) silvanae and L. tristis.

The viviparous species mostly belong to the first clades (sedis mutabilis archeforus group, nitidus group, lineomaculatus group and sylvanae group) of the indented tentative classification by Etheridge 
(1995). The majority of the cited species for the following clades of this classification are oviparous, but, according to the present study, some viviparous species are also scattered within either the chilensis or boulengeri groups.

To provide rational information from where data were obtained for any assumed reproductive mode, standardized criteria, such as those reported in Blackburn (1993a), were used. Egg laying habits of the oviparous species studied in this paper were directly checked by field or laboratory observations. Parturition in the field or evidence of births in captivity were always used to confirm assumptions on viviparous species. Species exhibiting uncertain evidence of viviparity, such as advanced oviductal foetuses, or developing oviductal eggs, etc. were excluded from this study.

The SVL and axilla-groin distances (AGD) were measured with an accuracy of $0.05 \mathrm{~mm}$.

Species were treated as individual data points (using the mean values) to avoid the possibility of pseudoreplication wherein the degrees of freedom may be greatly inflated (Hurlbert 1984).

Before using the mean of each sample as an individual data point homoscedasticity was checked by means of the Bartlett's test, to test the null hypothesis that the SD within each of the analysed species are the same. In cases of significant heteroscedasticity, those samples whose SD present a difference greater than 3 to 1 in relation to the average SD were omitted. In this case, the test was repeated without these samples to demonstrate their influence on heteroscedasticity.

Standardized skewness and standardized kurtosis were also tested, sample-by-sample, to determine whether each sample can be adequately modelled by a normal distribution (Zar 1996). In this case, sampling distributions with a standardized skewness and a standardized kurtosis in the interval $(-2,+2)$ were accepted as normal. Although arbitrary, this is a generally accepted cut-off for the recognition of normality.
Finally, the data used in this study (334 females: 194 from 18 oviparous species and 148 belonging to 12 viviparous species) included all the samples except those with a standardized skewness or a standardized kurtosis outside the interval $(-2,+2)$, and those that the Bartlett's test showed contributing to heteroscedasticity, according to the criteria referred above (the excluded samples were $L$. insolitus, L. sanjuanensis and $L$. uspallatensis).

Summary statistics for all data are presented (count, mean, SD, standardized skewness and standardized kurtosis).

For the comparison between viviparous and oviparous, a $t$-test was performed to compare the mean values of the two samples, assuming equal variances (this was determined by running an $F$-test to compare the SD of the two samples). As the $t$-tests and the $F$-tests depend on the samples from normal distributed populations, this assumption was first tested by running a set of tests across taxa within a reproductive mode, in order to determine whether each sample can be adequately modelled by a normal distribution (Zar 1996): the Shapiro-Wilk test, the standardized skewness test and the standardized kurtosis test.

To measure the hypothetical relationship between AGD (dependent variable) and SVL (independent variable) a regression analysis was performed. The regression model was chosen after comparison with alternative models. A simple linear model was chosen because of its explanatory power and because it does not differ significantly from any other model. These regression lines are graphically illustrated. In this context ANOVA statistics were used to test the statistical significance of the fitted relationship between AGD and SVL. To evaluate the degree of explanation of the fitted model the $R$-square was calculated.

Tests were carried out to compare fitted regression equations for a difference in slope (without regarding the intercepts) and also for a difference in intercept (without regard for the slopes), considering that the observed slopes and intercepts follow the $t$ distribution (Glantz 1997).

Table 1. Summary statistics for all species

\begin{tabular}{|c|c|c|c|c|c|c|c|c|c|}
\hline \multirow[b]{2}{*}{ Species } & \multirow[b]{2}{*}{$\mathrm{N}$} & \multicolumn{4}{|c|}{ SVL } & \multicolumn{4}{|c|}{ AGD } \\
\hline & & Mean & $\mathrm{SD}$ & st. sk. & st. kt. & Mean & SD & st. sk. & st. kt. \\
\hline Liolaemus anomalus & 10 & 64.64 & 5.36 & -0.90 & 0.27 & 31.68 & 3.21 & 0.58 & 0.43 \\
\hline Liolaemus bibroni & 16 & 50.28 & 2.79 & 0.88 & -0.04 & 23.75 & 1.12 & 0.52 & -0.50 \\
\hline Liolaemus boulengeri & 14 & 59.74 & 4.46 & 0.42 & -0.75 & 27.56 & 2.96 & 0.15 & -0.16 \\
\hline Liolaemus chacoensis & 10 & 47.17 & 2.97 & -0.11 & -0.27 & 21.97 & 2.34 & -0.54 & -0.85 \\
\hline Liolaemus chiliensis & 11 & 81.99 & 4.24 & 1.34 & 0.45 & 39.03 & 2.62 & 0.95 & -0.32 \\
\hline Liolaemus cuyanus & 10 & 73.52 & 5.33 & -0.88 & 0.16 & 33.27 & 2.98 & -1.12 & 0.36 \\
\hline Liolaemus darwinii & 14 & 55.14 & 3.94 & -1.30 & 0.39 & 25.46 & 1.99 & -0.43 & -0.87 \\
\hline Liolaemus fitzingeri & 10 & 79.50 & 4.88 & -0.98 & -0.18 & 38.55 & 3.14 & -1.21 & -0.21 \\
\hline Liolaemus fuscus & 14 & 42.99 & 2.38 & 0.22 & -1.34 & 20.91 & 1.42 & 0.21 & -1.05 \\
\hline Liolaemus gracilis & 10 & 51.62 & 2.36 & 0.54 & -0.08 & 23.09 & 1.61 & 0.98 & 0.83 \\
\hline Liolaemus melanops & 8 & 69.41 & 2.69 & -0.21 & -0.97 & 31.38 & 2.16 & 0.95 & -0.43 \\
\hline Liolaemus pseudoanomalus & 6 & 60.50 & 3.99 & 1.21 & -0.23 & 28.42 & 1.91 & -0.81 & -0.95 \\
\hline Liolaemus quilmes & 12 & 51.94 & 2.84 & -0.07 & -1.11 & 24.11 & 2.21 & 0.12 & -0.89 \\
\hline Liolaemus riojanus & 10 & 53.10 & 2.74 & -1.65 & 1.07 & 23.30 & 2.06 & -0.90 & 0.09 \\
\hline Liolaemus rothi & 6 & 79.00 & 6.13 & -0.75 & -0.68 & 34.08 & 2.62 & 0.81 & 0.54 \\
\hline Liolaemus scapularis & 10 & 50.61 & 3.69 & 0.05 & 0.19 & 22.15 & 2.66 & 0.13 & -0.51 \\
\hline Liolaemus tenuis & 14 & 54.35 & 4.13 & -1.81 & 1.60 & 22.91 & 2.36 & -1.36 & 1.16 \\
\hline Liolaemus xanthoviridis & 9 & 73.34 & 6.31 & 0.78 & -0.24 & 33.20 & 2.84 & 0.54 & -0.81 \\
\hline Liolaemus archeforus & 18 & 80.98 & 6.27 & -1.28 & -0.48 & 42.83 & 3.37 & -0.47 & -0.40 \\
\hline Liolaemus baguali & 8 & 78.00 & 5.02 & -0.35 & -0.48 & 41.84 & 2.06 & 0.08 & -0.03 \\
\hline Liolaemus gallardoi & 9 & 76.27 & 8.58 & 0.17 & -0.59 & 39.83 & 3.91 & -0.08 & -1.30 \\
\hline Liolaemus kingii & 14 & 76.75 & 7.07 & -0.21 & -0.73 & 40.82 & 4.03 & 0.45 & -1.09 \\
\hline Liolaemus lineomaculatus & 15 & 57.93 & 3.99 & -1.67 & 0.98 & 30.90 & 2.77 & -0.63 & 0.04 \\
\hline Liolaemus magellanicus & 9 & 57.78 & 4.63 & -0.11 & -0.06 & 30.61 & 2.74 & -0.83 & -0.51 \\
\hline Liolaemus ornatus & 12 & 59.21 & 5.11 & 0.51 & -0.18 & 29.83 & 3.99 & 1.43 & 0.92 \\
\hline Liolaemus periglacialis & 18 & 57.11 & 5.06 & -0.97 & -0.45 & 30.22 & 2.66 & -0.57 & 0.14 \\
\hline Liolaemus pictus & 11 & 57.41 & 6.75 & -0.63 & -0.97 & 29.93 & 3.30 & -0.40 & -0.98 \\
\hline Liolaemus sarmientoi & 16 & 76.29 & 6.24 & -1.83 & 1.64 & 40.30 & 4.01 & -1.48 & 1.33 \\
\hline Liolaemus silvanae & 7 & 72.36 & 4.03 & -0.82 & 0.36 & 37.53 & 2.30 & -1.28 & 0.21 \\
\hline Liolaemus tristis & 11 & 72.93 & 3.10 & 0.03 & 0.83 & 37.56 & 1.42 & 0.46 & -0.60 \\
\hline
\end{tabular}

$\mathrm{SVL}=$ snout-vent length; $\mathrm{AGD}=$ axilla-groin distance; $\mathrm{N}=$ sample size; mean = arithmetic mean; $\mathrm{SD}=$ standard deviation; st. sk. $=$ standardized skewness; st. kt. = standardized kurtosis. 
Table 2. Summary statistics for both oviparous and viviparous groups

\begin{tabular}{|c|c|c|c|c|c|c|c|c|c|}
\hline \multirow[b]{2}{*}{ Reproductive mode } & \multirow[b]{2}{*}{$\mathrm{N}$} & \multicolumn{4}{|c|}{ SVL } & \multicolumn{4}{|c|}{ AGD } \\
\hline & & Mean & SD & st. sk. & st. kt. & Mean & SD & st. sk. & st. kt. \\
\hline Oviparous & 18 & 61.05 & 12.25 & 0.76 & -1.02 & 28.04 & 5.85 & 1.00 & -0.82 \\
\hline Viviparous & 12 & 68.58 & 9.70 & -0.32 & -1.46 & 36.01 & 5.27 & -0.19 & -1.42 \\
\hline
\end{tabular}

SVL $=$ snout-vent length: $\mathrm{AGD}=$ axilla-groin distance: $\mathrm{N}=$ sample size; mean $=$ arithmetic mean; $\mathrm{SD}=$ standard deviation: st. sk. $=$ standardized skewness; st. kt. = standardized kurtosis.

Furthermore, a two-group discriminant analysis was performed for testing the hypothesis that the group mean values for SVL and AGD clusters are equal (Manly 1994).

The conventional, albeit arbitrary, alpha level is 0.05 .

The software used for statistical analysis was STATGRAPHICS Plus for Windows 4.0, Copyright (C1994-1999 by Statistical Graphics Corp.

\section{Results}

Summary statistics for all species are presented in Table 1 and summary statistics for both oviparous and viviparous groups are presented in Table 2 .

The female SVL of viviparous species is not significantly different from the female SVL of oviparous species $(t=1.79 ; \mathrm{df}=29 ; \mathrm{p}>0.05)$. However, a statistically significant difference was found concerning $\operatorname{AGD}(t=3.80 ; \mathrm{df}=29$; $\mathrm{p}<0.05)$.

Regression analysis results are shown in Fig. 1. The comparison between fitted regression equations showed a nonsignificant difference between the slopes at the $95 \%$ level $(F$-ratio $=3.49 ; \mathrm{p}>0.05)$, but a statistically significant difference among intercepts $(F$-ratio $=108.46 ; \mathrm{p}<0.05)$.

In relation to discriminant analysis, the canonical discriminating function $(-0.88-0.43 * \mathrm{SVL}+0.92 * \mathrm{AGD})$ is statistically significant at the $95 \%$ confidence level (Wilks Lambda $=0.19$; chi-square $=44.57, \mathrm{df}=2$ ).

The classification functions are, for oviparous females: $-16.60+1.23 * \mathrm{SVL}-1.54 * \mathrm{AGD}$, and for viviparous females: $-21.79-0.53 * \mathrm{SVL}+2.18 \mathrm{AGD}$.

In Fig. 2 AGD/SVL proportions in both oviparous and viviparous species are compared.

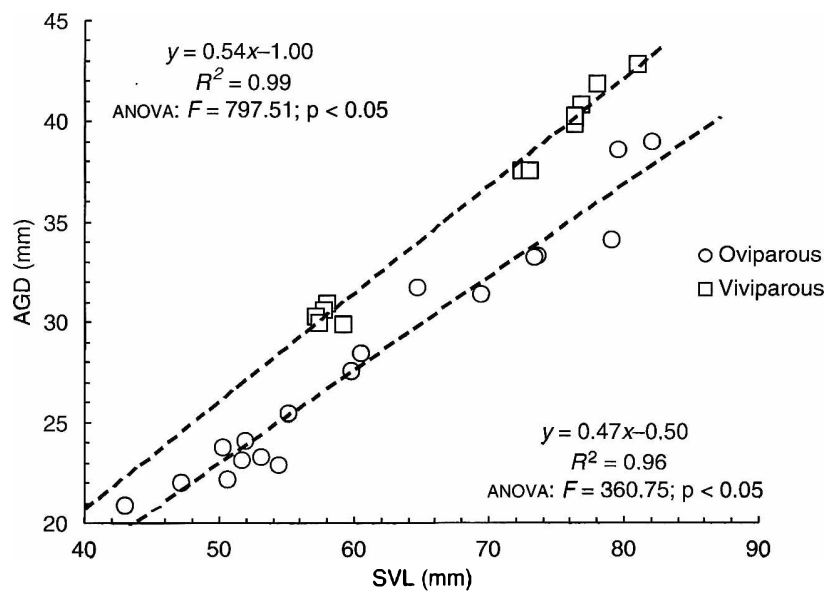

Fig. 1. Regression analysis between SVL and AGD in both oviparous and viviparous species. SVL = snout-vent length; $A G D=$ axilla-groin distance; $R^{2}=$ coefficient of determination; $F=F$-value from ANOVA statistics; $\mathrm{p}=$ alpha level for significance

\section{Discussion}

The statistically significant difference in AGD between oviparous and viviparous species reinforces the initial hypothesis that the species where placenta-like structures are found would most likely require an additional body cavity space for embryonal development: once the effect of overall size is removed, viviparous lizards in the genus Liolaemus have larger bodies than do oviparous species. That could be supported by generalized minor body-cavity space in the prevailing oviparous species. On the other hand an additional body-cavity space could be a morpho-functional characteristic of the more specialized iguanian groups where an embryonal development in placenta-like structures appeared. In addition, although the two groups may not differ in size, it is interesting to note that there are no small viviparous species.

Regression analysis suggests a very high correlation between SVL and AGD in both viviparous and oviparous species, and also an allometric difference between viviparous and oviparous Liolaemus species.

Therefore, it can be said that oviparous and viviparous females of the genus Liolaemus can be easily differentiated, with a high statistical confidence, by the study of the axillagroin/snout-vent relationship. AGD was shown to be a good size estimator of visceral cavity and a good indirect estimator of the mode of reproduction. As can be seen in Fig. 2, AGD surpassed $50 \%$ of SVL in viviparous females, while it is less than $50 \%$ in oviparous females.

Non-adaptive interpretations are possible. 'Shape' differences between egg-layers and live-bearers could result from allometry (if, for example, the live-bearers are consistently smaller in absolute size, then the difference in the proportional length of the axilla-groin component could simply reflect the overall size difference), or also from phylogenetic conservatism (if the live-bearers represent a single lineage, they may all be relatively long bodied simply because they have inherited this

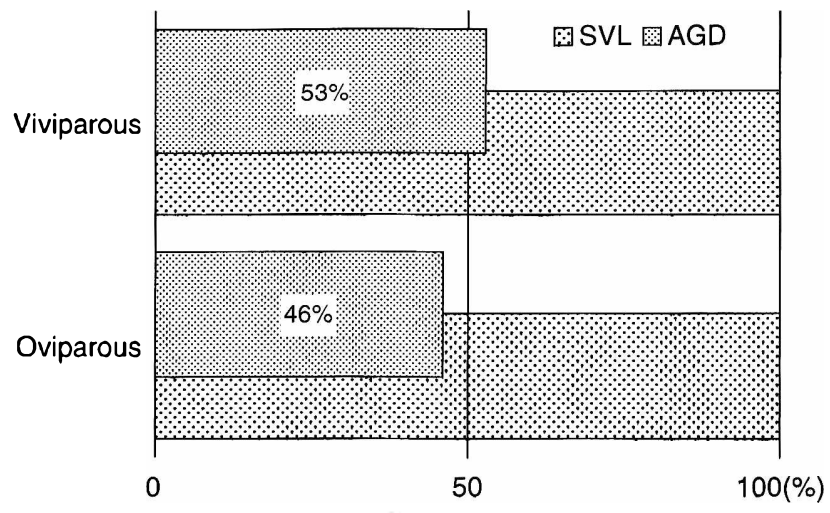

Fig. 2. AGD/SVLproportion in both oviparous and viviparous species. $\mathrm{SVL}=$ snout-vent length; $\mathrm{AGD}=$ axilla-groin distance 
trait from an ancestor); also, there may not be any functional relationship with reproductive mode. In fact, besides that viviparity led to evolution of a feature, Blackburn (2000) considered two other options for the association between viviparity and morphological features, such as a wide body cavity. The present analysis of species representing several lineages within Liolaemus, would add weight to the first hypothesis, compared with the other options analysed in Blackburn (2000): the presence of a wide cavity as a preadaptative feature for viviparity, and the coincidental presence of such feature and viviparity without an evolutive relationship. Indeed, Schulte et al. (2000) have already demonstrated by phylogenetic analyses multiple origins of viviparous reproduction among Liolaemus species. Their parsimony reconstruction of viviparity showed unequivocally three times the transition from oviparity to viviparity.

As adaptive hypotheses need a careful analysis, other correlated variables should also be taken into account. For example, if live-bearers occur at higher elevations than egglayers, then perhaps high elevations may cause the shift in body shape.

In summary, the present results show a clear allometric difference between oviparous and viviparous species, related with a higher body cavity space in viviparous species. No difference was found in the body size between these reproductive modes, refuting the conclusion of de Fraipont et al. (1996, 1999) for the genus Liolaemus. In this respect, Blackburn (1999) and Shine et al. (1999) noticed that several methodological and conceptual problems invalidated the conclusion of Fraipont et al. Further studies, taking into account phylogenetic relationships and environmental conditions, will show whether this difference is clearly correlated to reproductive mode or if other factors are also involved.

\section{Acknowledgements}

We would like to thank Richard Etheridge for his valuable comments and Daniel Blackburn for his enriching revision of the manuscript. We are also indebted to Stephen Tilley, Solveig Thorsteinsdóttir, Margarida Matos and Silvia Puig for the revision of the manuscript and suggestions. We also acknowledge with thanks the kind help given by Elena Gavetti, Curator of the Museo Regionale di Scienze Naturali at Turin, Italy, during our study of specimens of the herpetological collection at her care.

We are also very grateful to the following people who have generously permitted the study of their herpetological collections: J. Valencia's (Chile), A. Scolaro (Argentina), Centro Regional Universitario Bariloche, Univ. Nac. Comahue, Rio Negro (Argentina), Departamento de Biología de la Universidad de Chile, Santiago (Chile), Fundación Miguel Lillo, Tucumán (Argentina). Instituto Argentino de Investigaciones en Zonas Aridas, Mendoza (Argentina), Instituto de Biología Animal, Univ. Nac. Cuyo, Mendoza (Argentina), Instituto Patagónico de Punta Arenas (Chile), Museo Argentino de Ciencias Naturales, Buenos Aires (Argentina), Museo de Ciencias Naturales de La Plata, Buenos Aires (Argentina), Museo Regionale di Scienze Naturali di Torino (Italia), Museo Zoologico de la Universitá de Firenze (Italia), Museu de Zoologia, Universidade de São Paulo (Brasil), Museum National d'Histoire Naturelle, Paris (France), Museum of Comparative Zoology, Harvard University, Cambridge (USA), Kansas University Natural History Museum, Lawrence (USA) and Universidad de Los Andes, Mérida (Venezuela).

\section{Zusammenfassung}

Von der Oviparie zur Viviparie: Eine vorläufige Mitteilung zur morphometrischen Differenzierung zwischen den der Gattung Liolaemus zugeordneten oviparen und viviparen, Arten (Reptilia, Squamata, Tropiduridae).

Das Embryonenwachstum beansprucht in viviparen Eidechsenweibchen einen beachtlichen internen Raum und dieser Anspruch auf Raum sollte sich in ihrer externen Morphometrie wiederfinden. Es wurden externe morphologische Unterschiede, die mit dem Reproduktionsmodus in Zusammenhang stehen in 12 viviparen und 18 oviparen Arten von Eidechsen der Gattung Liolaemus erfaßt. Größenunterschiede zwischen viviparen und oviparen Arten wurden durch das Verhältnis der Längen Achselhöhle-Leiste zu MaulKloake entdeckt. Die Achselhöhle-Leisten Distanz, ein Wert, der als $\mathrm{Ma} ß$ des Bauchraums angesehen werden kann, überschritt 50 $\%$ der Maul-Kloaken-Länge bei den viviparen Weibchen, während sie bei den oviparen Weibchen stets unter $50 \%$ war. Dieser Unterschied zwischen den beiden Forpflanzungsweisen ist statistisch signifikant.

\section{References}

Blackburn, D. G., 1993a: Standardized criteria for the recognition of reproductive modes in Squamate Reptiles. Herpetologica 49, 118 132.

Blackburn, D. G., 1993b: Chorioallantoic placentation in Squamate Reptiles: structure, function, development and evolution. J. Exp. Zool. 266, 414-430.

Blackburn, D. G., 1995: Saltationist and punctuated equilibrium models for the evolution of viviparity and placentation. J. Theor. Biol. 174, 199-216.

Blackburn, D. G., 1998a: Reconstructing the evolution of viviparity and placentation. J. Theor. Biol. 192, 183-190.

Blackburn, D. G., 1998b: Structure, function and evolution of the oviducts of Squamate Reptiles, with special reference to viviparity and placentation. J. Exp. Zool. 282, 560-617.

Blackburn, D. G., 1999: Are viviparity and egg-guarding evolutionarily labile in Squamates? Herpetologica 55, 556-573.

Blackburn, D.G., 2000: Reptilian viviparity: past research, future directions, and appropriate models. A Comp. Biochem. Physiol. 127, 391-409.

Cabrera, A. L.; Willink, A., 1980: Biogeografia de América Latina. 2nd edn. Washington, DC, USA: Biological Series of the Organization of American States.

Callard, I. P.; Fileti, L. A.; Perez, L. E.; Sorbera, L. A.; Giannoukos, G.; Klosterman, L. L.; Tsang, P.; McCracken, J. A., 1992: Role of the corpus luteum and progesterone in the evolution of vertebrate viviparity. Amer. Zool. 32, 264-275.

Cei, J. M., 1986: Reptiles del centro, centro-oeste, y sur de la Argentina. Mus. Reg. Sci. Nat. Torino, Monogr. 4, 1-527.

de Fraipont, M.; Clobert, J.; Barbault; R., 1996: The evolution of oviparity with egg-guarding and viviparity in lizards and snakes: a phylogenetic analysis. Evolution 50, 391-400.

de Fraipont, M.; Clobert, J.; Meylan, S.; Barbault, R., 1999: On the evolution of viviparity and egg-guarding in squamate reptiles a reply to R. Shine and M. S. Y. Lee. Herpetologica 55, 550-555.

Etheridge, R., 1995: Redescription of Ctenohlephary's adspersa Tschudi, 1845, and the taxonomy of Liolaeminae (Reptilia: Squamata: Tropiduridae). Am. Mus. Nov. 3142, 1-34.

Glantz, S. A., 1997: Primer of Bio-statistics. 4th edn. New York, USA: McGraw-Hill

Guillette. L. J. Jr., 1982: The evolution of viviparity and placentation in the high elevation, Mexican lizard Sceloporus aeneus. Herpetologica 38, $94-103$.

Hurlbert. S. H., 1984: Pseudoreplication and the design of ecological field experiments. Ecol. Monog. 54, 187-211.

Manly, B. F. J., 1994: Multivariate Statistical Methods - A Primer. 2nd edn. London, England: Chapman \& Hall.

Schulte, J. A., Macey, J. R., Espinoza, R. E., Larson, A., 2000: Phylogenetic relationships in the iguanid lizard genus Liolaemus: multiple origins of viviparous reproduction and evidence for recurring Andean vicariance and dispersal. Bio. J. Linn. Soc. 69, 75-102. 
Shine, R., 1983: Reptilian reproductive modes: The oviparity-viviparity continuum. Herpetologica $39,1-8$.

Shine, R., 1995: A new hypothesis for the evolution of viviparity in reptiles. Amer. Nat. 145, 809-823.

Shine, R.; Lee, M. S. Y., 1999: A reanalysis of the evolution of viviparity and egg-guarding in squamate reptiles. Herpetologica 55, 538-549.

Tinkle, D. W.; Gibbons, J. W., 1977: The distribution and evolution of viviparity in reptiles. Misc. Publ. Mus. Zool. Univ. Mich. 154, $1-55$.
Zar, J. H., 1996: Biostatistical Analysis. 3rd edn. Upper Saddle River, New Jersey, USA: Prentice-Hall International, Inc.

Author's addresses: Jose Miguel Cei, Dept. Cs. Naturales, Univ. Nac. Rio Cuarto, Córdoba, Argentina; Fernando Videla, Unidad de Ecologia Animal, IADIZA (CONICET). CC. 507, 5500, Mendoza, Argentina; Luis Vicente (for correspondence), Centro de Biologia Ambiental/DZA, Fac. Ciências. Univ. Lisboa. Campo Grande, Lisboa, Portugal. E-mail: Ivicente $(a$ fc.ul.pt 